\title{
Verification of MATLAB/Simulink Power Cable Modelling with Experimental Analysis
}

\author{
Tze Mei Kuan, Suhaila Sulaiman, Azrul Mohd. Ariffin, \\ Wan Mohamad Shakir Wan Shamsuddin \\ Department of Electrical Power Engineering, College of Engineering, \\ Universiti Tenaga Nasional, Jalan IKRAM-UNITEN, 43000 Kajang, Malaysia
}

\begin{tabular}{l}
\hline \hline Article Info \\
\hline Article history: \\
Received Feb 1, 2018 \\
Revised Apr 21, 2018 \\
Accepted Apr 27, 2018 \\
\hline
\end{tabular}

Keywords:

Cable defects

Cables joints

MATLAB/Simulink

Time domain reflectometry

\begin{abstract}
Cross-linked polyethylene (XLPE) power cable is commonly used as the medium for transmitting power supply in the power system network. However, frequent exposure of XLPE cable to the high voltage causes its insulation to degrade over time leading to electricity outages. Degradation of cable can be prevented if regular maintenance is performed using the accurate assessment method. This study models and simulates a cable system comprising of three cable sections connected by two un-degraded cable joints. This model aims to assess defect along the tested cable with the application of time domain reflectometry (TDR) technique. A series of simulations are conducted by varying the cable insulation condition to study its influence on the cable joint reflection. These simulation results from MATLAB/Simulink are validated against the actual TDR experimental results. The identical results shown between the simulation and experimental results indicate that the cable model is valid and can be used to assess the condition of a cable.
\end{abstract}

Copyright (C) 2018 Institute of Advanced Engineering and Science. All rights reserved.

\section{Corresponding Author:}

Tze Mei Kuan,

Department of Electrical Power Engineering, College of Engineering,

Universiti Tenaga Nasional, Jalan IKRAM-UNITEN, 43000 Kajang, Malaysia.

Email: tzemei@uniten.edu.my

\section{INTRODUCTION}

Power cable is a medium for supplying power to consumers. Thus, it is crucial for power utility to ensure these cables are well maintained to provide a reliable power system. However, frequent exposure of these cables to high voltage causes the cable insulation to degrade over time and finally breakdown occurs resulting in electricity outages. Degradation of cable can be caused by several factors such as partial discharge, voids, water treeing, faulty cable joint and others [1-7]. Hence, performing regular maintenance of power cable is important so that defects in the cable can be diagnosed at the early stage to prevent major outages.

Power utilities have been applying various techniques [8-12] for cable defect diagnosis however, most techniques are unable to pinpoint the defect location along the tested cable and some techniques are destructive [12-14]. Recent studies in [15-18] have suggested that the reflectometry technique is the most suitable approach and is non-destructive. Reflectometry technique works by sending a pulse to the test cable and any reflection noticed along the cable indicates impedance discontinuity which can be due to defect or cable jointing [18]. Thus, with proper recognition of the reflected pulse pattern, the location of the defect can be pinpointed at the point of reflection.

This study aims to assess defect along tested cable with the application of time domain reflectometry (TDR) technique through a cable model built using MATLAB/Simulink. This work is an extension of study in [19]. A cable system comprising of three cable sections connected by two un-degraded cable joints is modelled and simulated using MATLAB/Simulink with the application of TDR technique. 
A series of simulations are conducted by varying the cable insulation condition to study its influence on the cable joint reflection. These simulation results from MATLAB/Simulink are validated against the actual TDR experimental results from [20]. Experimental results obtained from study in [20] are measured using Megger Teleflex SX TDR equipment on cable sample of a single core $240 \mathrm{~mm}^{2} 11 \mathrm{kV}$ unarmoured XLPE cable (aluminum conductor) with cable length fixed at 300m for all experiments. Hence, all parameters set in the MATLAB/Simulink model are the same as parameters from the experiments conducted to ensure results are validated accurately.

\section{METHODOLOGY}

\subsection{Cable Configurations for MATLAB/Simulink Simulation}

This research extends the study in [19] where the previous study compares the simulation results for single cable without joint and cables with a single joint with the experimental results from [20]. Hence, this work further verifies the capability of the cable model built using MATLAB/Simulink in identifying defects along the cable by increasing the number of cable joint. Figure 1 shows the cable configurations of three $100 \mathrm{~m}$ cable sections connected using two cable joints. The cable joint used in this study is the same as [19] which is un-degraded. Table 1 lists the series of simulations with various combinations of cable insulation condition tested using MATLAB/Simulink. The cable insulation condition is varied to investigate its influence on the TDR reflection result especially at the cable joint reflection.

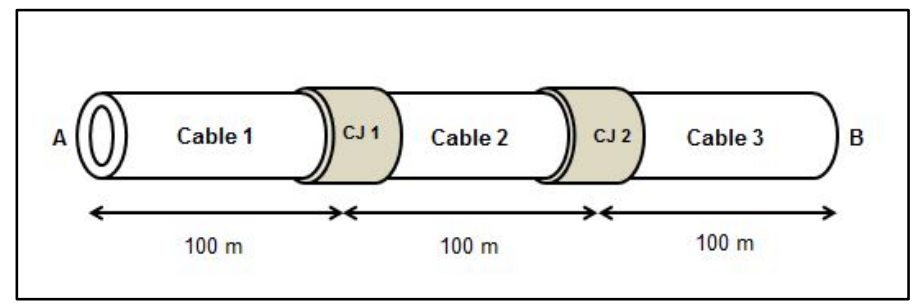

Figure 1. Cable configuration for three $100 \mathrm{~m}$ connected by two cable joints (CJ 1 and CJ 2)

Table 1. Combinations of XLPE cables for simulation

\begin{tabular}{|c|c|c|c|c|c|}
\hline Simulation & $\begin{array}{c}\text { Cable } 1 \\
100 m\end{array}$ & \multirow{8}{*}{ 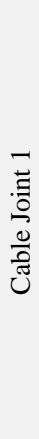 } & $\begin{array}{c}\text { Cable } 2 \\
100 \mathrm{~m}\end{array}$ & \multirow{8}{*}{ 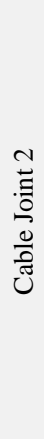 } & $\begin{array}{c}\text { Cable } 3 \\
100 \mathrm{~m}\end{array}$ \\
\hline 1 & Ideal & & Ideal & & Ideal \\
\hline 2 & Ideal & & Ideal & & Degraded \\
\hline 3 & Ideal & & Degraded & & Ideal \\
\hline 4 & Degraded & & Ideal & & Ideal \\
\hline 5 & Degraded & & Degraded & & Ideal \\
\hline 6 & Degraded & & Ideal & & Degraded \\
\hline 7 & Ideal & & Degraded & & Degraded \\
\hline
\end{tabular}

\subsection{Modelling of TDR technique Cable Assessment System in MATLAB/Simulink}

Figure 2 shows the full cable system model built in MATLAB/Simulink for the simulations of three $100 \mathrm{~m}$ cable sections connected with two cable joints. The cable model in Figure 2 is slightly modified from the cable models in [19] by adding another lumped parameter model to represent the second cable joint which connects test cable 2 and 3. All parameter settings of the pulse generator, cable block diagram and lumped parameter models remained the same as the settings from study in [19]. 


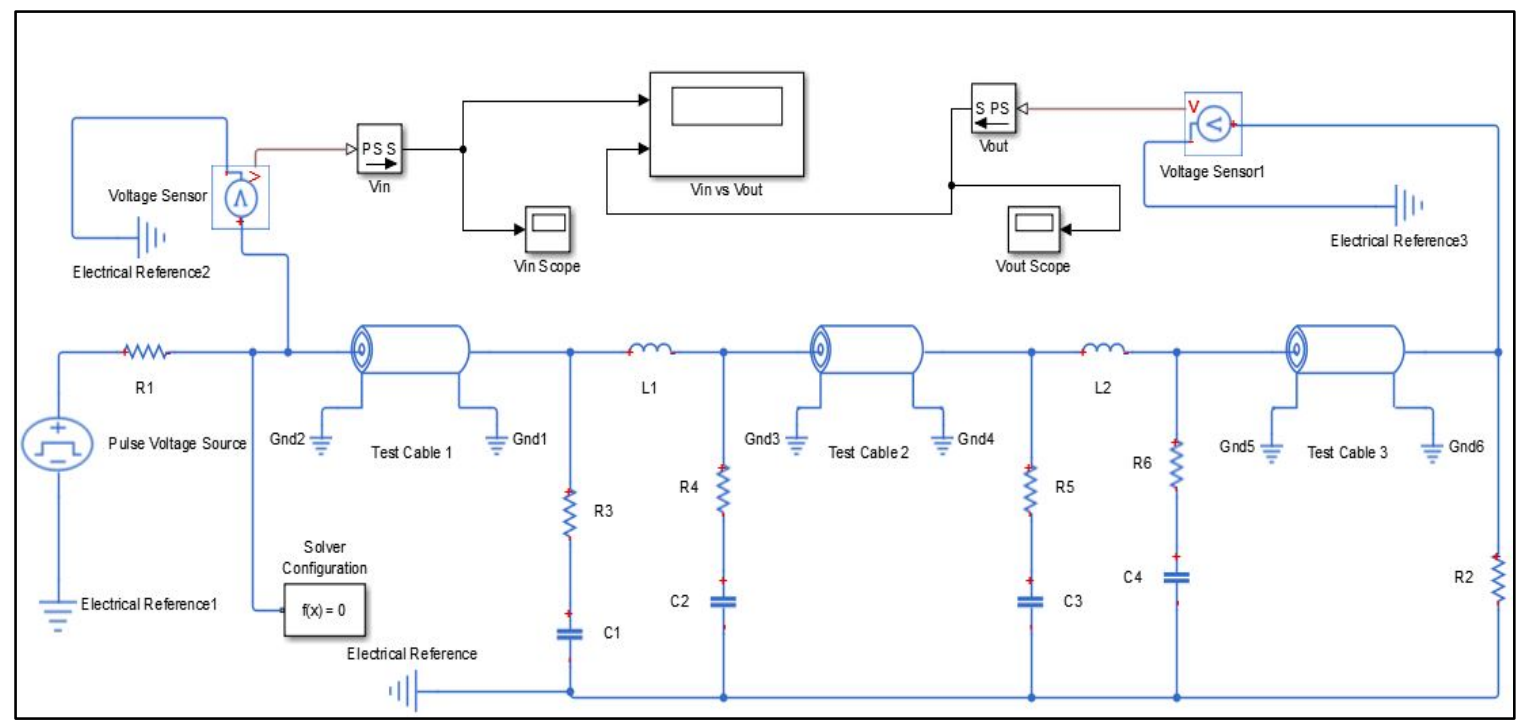

Figure 2. Cable system model in MATLAB/Simulink

\subsection{Validation of TDR Simulation}

Table 1 simulation results are verified against the experimental results conducted by study in [20] to investigate the reliability of the cable model in producing consistent results with the addition of third cable section and second cable joint.

\section{RESULTS, ANALYSIS AND DISCUSSIONS}

Cable configurations in Table 1 can be classified into three categories; ideal cable with two cable joints, one cable section degraded with two cable joints and two cable sections degraded with two cable joints. The following sections discusses the results and analysis from these three categories.

\subsection{Ideal Cable with Two Cable Joints}

Figure 3 shows simulation 1 result using the MATLAB/Simulink cable model in Figure 2 where all three cable sections are in good conditions including the two cable joints. Four reflections are observed from Vin. The first reflections at the starting point denotes the injected pulse from the pulse generator while the other three are reflected at $1 \mu \mathrm{s}, 2 \mu \mathrm{s}$ and $3 \mu \mathrm{s}$, respectively. As explained in [19], the x-axis in MATLAB/Simulink is limited to time parameter only. However, this can be translated to cable length by using the time delay equation [21]. By applying the time delay equation, the reflections at $1 \mu \mathrm{s}, 2 \mu \mathrm{s}$ and $3 \mu \mathrm{s}$ represents the reflections at cable length of $100 \mathrm{~m}, 200 \mathrm{~m}$ and $300 \mathrm{~m}$, respectively. This indicates that the second reflection refers to the first cable joint since it is located between the first $100 \mathrm{~m}$ cable and second $100 \mathrm{~m}$ cable. The third reflection is detected at $200 \mathrm{~m}$ which indicates the reflection from the second cable joint since it connects the second $100 \mathrm{~m}$ cable and third $100 \mathrm{~m}$ cable. The fourth reflection is identified at $300 \mathrm{~m}$ which denotes the endpoint reflection of the whole $300 \mathrm{~m}$ tested cable.

It can be observed that the two cable joints reflections identified at $100 \mathrm{~m}$ and $200 \mathrm{~m}$ show a pair of positive and negative reflections with same magnitude each which is consistent with the hypothesis made in [19] where a good joint connecting two good cables shows a pair of reflections with same magnitude. In order to verify this simulation result, it is compared to the experimental result as illustrated in Figure 4. It is clearly observed that the experimental result show similar reflections as the simulated result. 


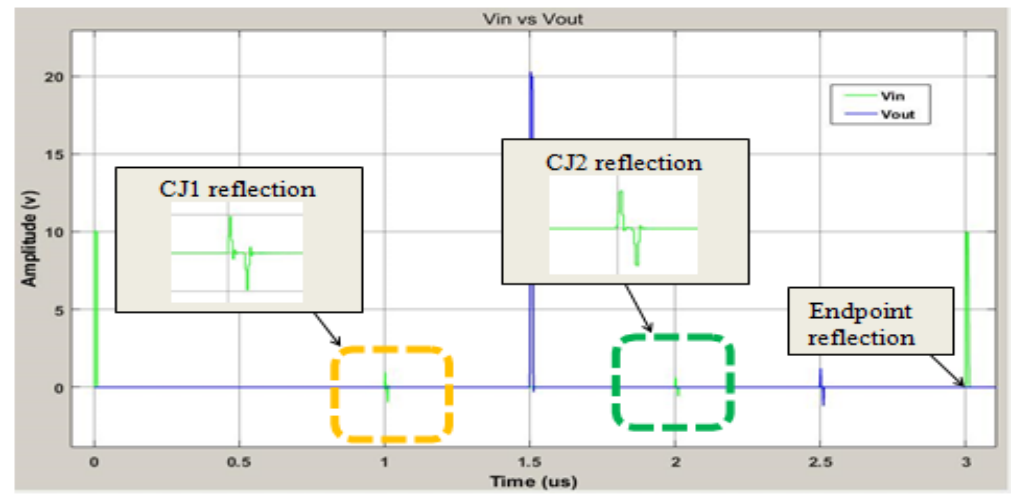

Figure 3. Simulation 1 result

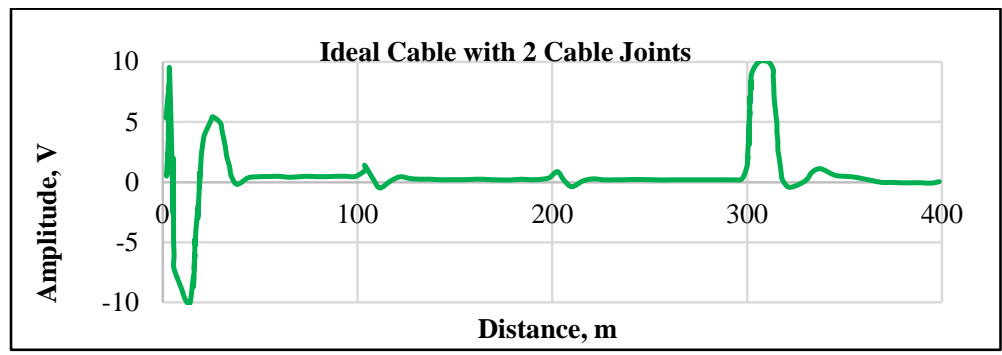

Figure 4. Experimental result for ideal cable with 2 joints [20]

\subsection{One Cable Sections Degraded with Two Cable Joints}

Simulations 2 to 4 are cable configurations with only one of the three cable sections is degraded. According to the hypothesis made in [19], in the occasion where a cable section is degraded, the cable joint reflection closest to the degraded cable will show higher magnitude compared to its pair. All three results from simulations 2 to 4 are found to have similar characteristics as the hypothesis made in [19]. The endpoint reflections for these simulations are also observed to be slightly delayed since a cable section is degraded. Figure 5 shows simulation 3 result where the second cable section is degraded. Since the degraded cable is located between two cable joints, hence the closest cable joint reflections which are the negative reflection from the first cable joint and the positive reflection from the second cable joint show higher magnitude than its respective pair. Validating this result with the experimental result from Figure 6, it is clearly noticeable that the cable joint reflections characteristics are identical.

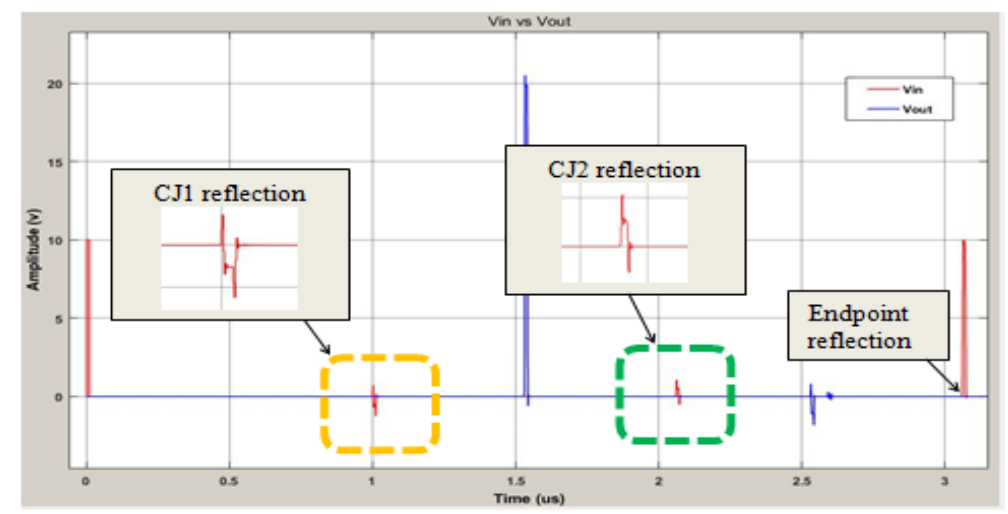

Figure 5. Simulation 3 result 


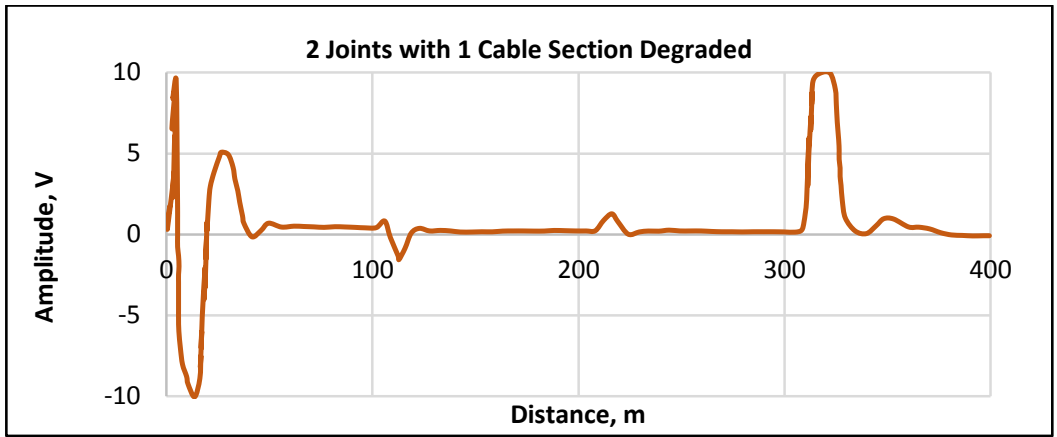

Figure 6. Experimental result for 1 cable section degraded with 2 joints [19]

\subsection{Two Cable Sections Degraded with Two Cable Joints}

Simulations 5 to 7 from Table 1 are cable configurations with two of the three cables in degraded condition connected by two good joints. The MATLAB/Simulink simulation results have shown same characteristics which also satisfies the hypothesis discussed in section 3.2. This can be illustrated by Figure 7 which shows the result of Simulation 7. Simulation 7 comprises of two degraded cables which are located at the second and third cable sections. With the hypothesis from section 3.2, the negative reflection from the first cable joint shows higher magnitude compared to its positive reflection since the negative reflection is closest to the degraded cable at the second cable. The second cable joint reflection however shows both positive and negative reflections with same magnitude. This is because the third cable is having the same degraded condition as the second cable. Hence, same magnitude is observed. Although the magnitudes are the same, the cable can still be identified as degraded due to the delay observed by the reflections of the second joint which is located after $2 \mu$ s while the endpoint reflection is recorded with a delay twice the delay observed at the second cable joint. Thus, it can be concluded that the second and third cables are degraded.

Results from simulations 5 to 7 are also verified against the experimental results from [20]. From the comparisons conducted, the characteristics of the cable joint reflections from MATLAB/Simulink simulation results are still showing consistent results with the experimental results in [20]. For instance, simulation 7 result in Figure 7 can be compared to Figure 8 experimental result which show identical reflections. Thus, it can be concluded that the cable model in Figure 2 is valid and can be used for further investigations on cable defect assessment.

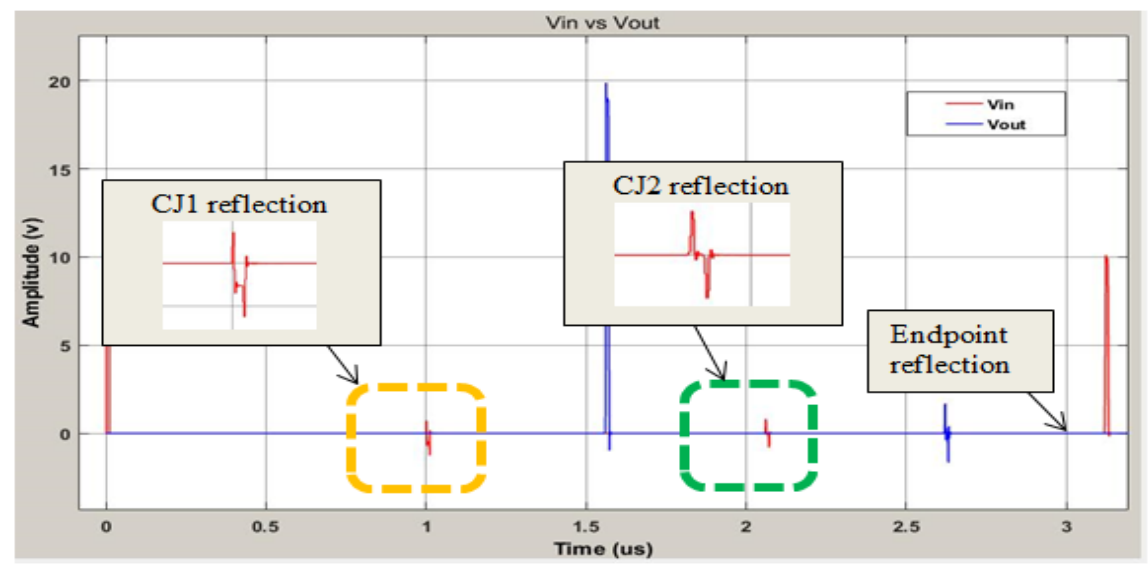

Figure 7. Simulation 7 result 


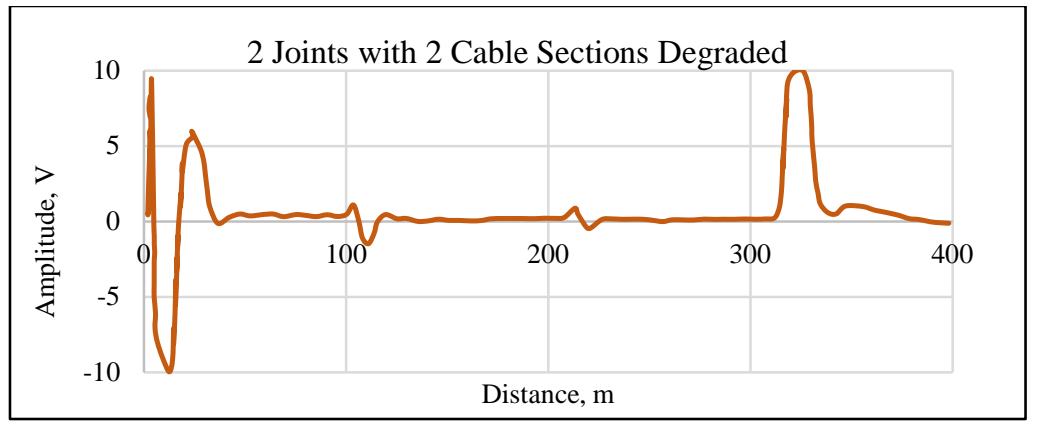

Figure 8. Experimental result for 2 cable sections degraded with 2 joints [16]

Table 2 summarizes the comparisons between MATLAB/Simulink simulation results and the experimental results from [20] which shows the changes in the cable joint reflections with different cable condition connected to the joint.

Table 2. Comparisons of cable joint reflection between MATLAB/Simulink simulation and experimental results

(a) Observation at Cable Joint 1 (CJ 1)

Simulation

(b). Observation at Cable Joint 2 (CJ 2)

Simulation




\section{CONCLUSION}

This research extends the cable model verification from study in [19] where this study models a cable system with two joints using MATLAB/Simulink. A series of simulations are conducted by using various combinations of cable conditions to replicate actual cable with defects along the cable. The methodology of simulation is divided into three categories where simulation is performed first on cable configuration having all three cables in ideal condition as a benchmark to compare with results from cable configurations with degraded cable later. Next category of simulations is conducted on cable configurations with one degraded cable section and lastly, simulations are done with cable configurations having two cable sections in degraded condition. These simulation results are compared to the experimental results from study in [20] to verify the accuracy and reliability of the cable system model for defect assessment.

Simulation results obtained in this study have shown the same characteristics of cable joint reflections as the hypothesis made in previous study [19]. Comparison of results between simulation and experimental results also show consistency where the characteristics of cable joint reflections are identical for both cases. Therefore, it has been validated that the cable system modelled in MATLAB/Simulink is as accurate as the actual cable condition and hence, the MATLAB/Simulink model can be used for further studies in assessing defects in cables. In addition, this cable model can be investigated further by modelling a degraded joint and be validated against the experimental results since this study only emphasizes undegraded cable joint.

\section{ACKNOWLEDGEMENTS}

The authors would like to thank the Ministry of Education, Malaysia for funding this project under the Fundamental Research Grant Scheme (20140121FRGS) and the High Voltage Diagnostics team from TNB Research Sdn. Bhd. for their full support in laboratory facilities, technical support and cable samples.

\section{REFERENCES}

[1] Kai Zhou, Wei Zhao and Xiantao Tao, "Toward Understanding the Relationship between Insulation Recovery and Micro Structure in Water Tree Degraded XLPE Cables,” IEEE Transactions on Dielectrics and Electrical Insulation, Vol. 20 (6), December 2013, pp. 2135-2142.

[2] J. Densley, “Ageing Mechanisms and Diagnostics for Power Cables - An Overview,” IEEE Electrical Insulation Magazine, Vol. 17 (1), January 2001, pp. 14-22.

[3] S. Boggs and J. Densley, "Fundamentals of Partial Discharge in the Context of Field Cable Testing," IEEE Electrical Insulation Magazine, Vol. 16 (5), September 2000, pp. 13-18.

[4] E. Gulski, F. J. Wester, J. J. Smit, P. N. Seitz and M. Turner, "Advanced Partial Discharge Diagnostic of MV Power Cable System using Oscillating Wave Test System,” IEEE Electrical Insulation Magazine, Vol. 16 (2), March 2000, pp. 17-25.

[5] Qiang Gao, Zaiming Yu, Xiaoming Li, Qi Liu, Fang Yuan, Yue Han, Lin Shi, Jixian Shen and Zhaohui Liang, "On Line Monitoring of Partial Discharge in High Voltage Cables,” TELKOMNIKA Indonesian Journal of Electrical Engineering, Vol. 4 (3A), September 2016, pp. 108-114.

[6] Zhang Weixia, Zhao Xianping, Zhao Shutao, Yu Hong and Wang Dada, "Study on Partial Discharge Detection of 10kV Power Cable,” TELKOMNIKA Indonesian Journal of Electrical Engineering, Vol. 10 (7), November 2012, pp. 1795-1799.

[7] S. Hvidsten, E. Ildstad, J. Sletbak and H. Faremo, "Understanding Water Treeing Mechanisms in the Development of Diagnostic Test Methods," IEEE Transactions on Dielectrics and Electrical Insulation, Vol. 5 (5), October 1998, pp. 754-760.

[8] David L. McKinnon, “Insulation Resistance Profile (IRP) and Its Use for Assessing Insulation Systems,” IEEE International Symposium on Electrical Insulation (ISEI), San Diego, June 2010, pp. 1-4.

[9] J. L. Parpal, J. F. Drapeau, C. Potvin, D. Jean, D. Lalancette and P. E. Beaudoin, "Water-Tree Aging Characterization of MV XLPE Cable Insulation using Time Domain Spectroscopy (TDS)," 19th International Conference on Electricity Distribution, CIRED 2007, Vienna, May 2007, pp. 1-4.

[10] Yigang Liu, Xue Chang and Gang Liu, “Analysis of AC Voltage Withstand Test of HV XLPE Power Cable,” IEEE International Conference on Solid Dielectrics, Winchester, U.K., July 2007, pp. 666-668.

[11] C. M. Walton, "Detecting and Locating MV Failure before It Occurs. Experience with live line partial discharge detection on underground paper insulated $11 \mathrm{kV}$ cables in London," International Conference on Electricity Distribution, CIRED 2001, Amsterdam, June 2001.

[12] Katsumi Uchida, Yoichi Kato, Masahiko Nakade, Daisuke Inoue, Hiroyuki Sakakibara and Hideo Tanaka, "Estimating the Remaining Life of Water-Treed XLPE Cable by VLF Voltage Withstand Tests," Asia Pasific IEEE PES Transmission and Distribution Conference and Exhibition, Vol. 3, October 2002, pp. 1879-1884.

[13] Muhammad Yahya and Muhammad Nazrolni Azmi bin Izani, "Cable Test and Breakdown Voltage Determination of Joysense Cable Insulation,” Indonesian Journal of Electrical Engineering and Computer Science, Vol. 8 (1), October 2017, pp. 177-183. 
[14] Jery Althaf, Muhammad Imthiaz and Rejith Raj, “Underground Cable Fault Detection using Robot,” International Journal of Electrical and Computer Engineering, Vol. 3 (2), April 2013, pp. 145-151.

[15] Philip A. Martnez and Joel Joseph S. Marciano, "A Simulation Study of A Time Domain Reflectometry (TDR) Cable with Non-Standard Cross-Section,” TENCON 2014, 22-25 October 2014, Bangkok, Thailand.

[16] Y. J. Shin, E. J Powers, T. S. Choe, Chan-Young Hong, Eun-Seok Song, Jong-Gwan Yook and Jin Bae Park, "Application of Time-Frequency Domain Reflectometry for Detection and Localization of a Fault on Coaxial Cable,” IEEE Transactions on Intrumentation and Measurement, Vol. 54 (6), December 2005.

[17] P. Smith, C. Furse and J. Gunther, "Analysis of Spread Spectrum Time Domain Reflectometry for Wire Fault Location,” IEEE Sensors Journal, Vol. 5 (6), December 2005.

[18] Scott B. Jones, Jon M. Wraith and Dani Or, "Time Domain Reflectometry Measurement Principles and Applications,” Hydrological Processes, Vol. 16 (1), January 2002, pp. 141-153.

[19] Tze Mei Kuan, Suhaila Sulaiman, Azrul Mohd. Ariffin and Wan Mohamad Shakir Wan Shamsuddin, “MATLAB/Simulink Power Cable Modelling for Cable Defects Assessment,” Paper accepted in 2018 International Conference on Electrical Engineering and Computing, 24-25 March 2018, Malaysia.

[20] Tze Mei Kuan, Azrul Mohd. Ariffin and Maria Madelina Bemmynser Sedau, "Advancement of TDR Technique for Locating Power Cable Insulation Degradation,” International Journal on Advanced Science Engineering Information Technology, Vol. 7 (6), 2017, pp. 1976-1982.

[21] T. M. Kuan, A. Mohd Ariffin and S. Sulaiman, "Signal Analysis to Detect Water Tree Location in Polymeric Underground Cables,” 2011 IEEE Student Conference on Research and Development, Cyberjaya, 2011, pp. 277282. 